\title{
The Functional Value of Morphological and Grammatical Movement
}

\author{
Zyad A. Abdussamad Albanna \\ Faculty of Education, Salahaddin university, Iraq \\ dr.zyadalbanna@gmail.com
}

\begin{abstract}
:
Arabic is one of the synthetic languages, and it is one of the most languages that branch into various sciences and departments. Among these sciences is semantics, which is a wide-area science, intertwined with parts, broadening relationships with other linguistic, structural, and structural linguistic levels, in addition to its relations with many human sciences and knowledge such as philosophy, jurisprudence, and science. Speech, and others, and specialized in Arabic features that made it known and clearly defined among other languages, and among these features are movement and what it performs of indications, whether morphological in the structures of words or grammatical in the end, and this research tries to stand at the importance of these movements and reveal the indications that suggest and gain the lexical singular New connotations.
\end{abstract}

Keywords: Semantics; Function; Movement; Morphological Movement; Grammatical Movement.

Crossref doi https://doi.org/10.51345/.v32i1.315.g186 


\section{القيمة الوظيفية للحر كة الصرفية والنحوية \\ أ.م.د. زياد عبد الله عبد الصمد البّّا \\ كلية التربية، جامعة صلاح الدين، العراق \\ dr.zyadalbanna@gmail.com}

\section{ملخص البـحث}

العربيّة من اللغات التركيبية، ومن أكثر اللغات التي تتفرّع إلى علوم وأقسام متنوّعة، ومن هذه العلوم علم الدلالة وهو علم فسيح الأرجاء، متداخل الأجزاء، متّسع العلاقات مع المستويات اللغوية الأخرى الصوتية والبنائية والتركيبة، زيادة على علاقاته بعلوم ومعارف إنسانية كثيرة كالفلسفة، والفقه، وعلم الكلام، وغيرها، واختصّت العربية بميزات جعلتها معروفة واضحة المعالم بين اللغات الأخرى، ومن هذه الميزات الحركة وما تؤديها من دلالات سواء كانت صرفية في بنى الكلمات أم أم نحوية في أواخرها، وهذا البحث يحاول الوقوف عند أهمية هذه الحركات والكشف عن الدلالات التي توحيها وتكسب المفردة

$$
\text { المعجمية دلالات جديدة. }
$$


المقدمة:

تواصل العلماء واللغويون في العناية باللغة العربية والحفاظ عليها كونها لغة القرآن الكريم، فألّفوا في ذلك الكتب والمعاجم والمجلدات، لإرساء قو اعدها، وتثبيت دعائمها، وحمايتها، فكانت بحوثهم ودر اساتهم مناراً للأجيال من بعدهم. والعربيّة من اللغات التركيبة، ومن أكثر اللغات التي تتفرّع إلى علوم وأقسام متنوّعة، ومن هذه العلوم علم الدلالة وهو علم فسيح الأرجاء، متداخل الأجزاء، متّسع العلاقات مع المستويات اللغوية الأخرى الصوتية والبنائية والتركيبية، زيادة على علاقاته بعلوم ومعارف إنسانية كثيرة كالفلسفة، والفقه، وعلم الكلام، و التاريخ، والجغرافية، والاجتحاع، وغيرها من العلوم التي يبدو بعضها شديد الاشتباك بعلم الدلالة، وهو من أهم هذه الفروع وأعقدها وأمتعها في آن واحد، فهو هام لأنه يبحث في المعنى الذي هو الوظيفة الرئيسة للغة، وهو معقد لأنه يبحث في أمور مجردة متشعبة ذات طبيعة فلسفية نفسية، وهو متع لأن اقتحامه على ما فيه من تعقيد يعطي الباحث متعة ذهنية راقية، والدلالة (semantics)، يُعرّف بأنه: " دراسة المعنى، أو العلم الذي يدرس المعنى، أو ذلك الفرع من علم اللغة الذي يتناول المعنى، أو ذلك الفرع الذي يدرس الشروط الواجب توافرها في الرمز حتى يكون قادراً على حمل المعنى"، ومن الأمور التي يعتمد عليها في توجيه المعنى الحركة (الصائت القصير) سواء كانت صرفية أم نحوية، للفصل بين المعاني وهذا البحث قائم على ذلك.

\section{المحور الأول: علم الدلالة ظهوره ونشأته :}

من المعروف أن علم الدلالة علم حديث النشأة، ظهر أولياته ويو ادره في أواخــــ القرن التاسع عشر، وهذا لا يعني مطلقاً أنَّ التفكير الإنساني في العصور القديمة في مجال اللغة يخلو من دراسات تهتم بالمعنى (1)، لكن التنظير والتقنين لهذا العلم بدا حديثاً. أما منبع ظهور هذا العلم (2) - مستقلاً أو كجزء من علم اللغة أو اللسانيات - فكان لليونان أثرهم البيّن في بلورة مفاهيم لها صلة قيّمة بعلم الدلالة، فلقد حاور (أفلاطون) أستاذه (سقراط) حول علاقات قائمة بين 
اللفظ ودلالته، وكان أفلاطون يميل إلى القول بالعلاقة الطبيعية بين الدال ومدلوله، وأخذ سقراط يمني النفس بتلك اللغة المثالية التي تربط بين ألفاظها ومدلو لاتها ربطا طبيعيا ذاتياً، كتلك الألفاظ المشتقة من

$$
\text { أصوات الطبيعة من حفيف وخرير وزفير. }
$$

أمَّـا عند الهنود، فقد جذب هذا الموضوع اهتحام الهنود، ربحا قبل اهتحام اليونانيين، بتعدد الآراء حول العلاقة بين اللفظ والمعنى، فمنهم مَنْ رفض فكرة التباين بين اللفظ والمعنى، ومنهم من رأى بأن العلاقة بين اللفظ والمعنى علاقة وطيدة وفطرية(3)، ولقد كان لعلم)ء اللغة الهنود عناية كبيرة باللغة، وكتاب الهنود الديني (الفيدا) منبع الدراسات اللغوية والألسنية، ومن جملة الآراء التي أوردها العلماء المنود حول نشأة اللغة قولهم بوجود علاقة ضرورية بين اللفظ والمعنى. وكان لعلماء الرومان جهد مُعتبر في الدراسات اللغوية؛ خاصَّة ما تعلَّق منها بالنحو، وإليهم يرجع الفضل في وضع الكتب المدرسية، وبلغت العلوم اللغوية من النّضج والثَّاء مبلغًا كبيرًا في العصر الوسيط مع المدرسة السكو لائية (Scolastique) و التي احتدم فيها الصِّراع حول طبيعة العلاقة بين الكلمات ومدلو لاتها(4). وفي حدود القرن التاسع عشر الميلادي تطورت الدراسات اللغوية، ولم يكن علم الدلالة قائماً بذاته - كعلم مستقل -، وهذا ما جعل اللغويين أكثر تخصصاً في البحث عن اللغة، فظهرت النظريات اللسانية وتعددت المناهج، فبرزت (الفونولوجيا) التي اهتمت بدراسة وظائف الأصوات، كما ظهر علم (الفونتيك) الذي يهتم بدراسـة الأصوات المجردة، وبرزت (الأتيمولوجيا) التي اعتنت بدراسة الاشتقاقات في اللغة، ومن ثم ظهور علم التراكيب الذي يختص بدراسة الجانب النحوي وربطه بالجانب الدلالي في بناء الجملة، وأصبح علم الدلالة (السيمانتيك) علمًا مستقلاً قائًًا بذاته، ولقد ظهرت أولياته وبوادره خلال القرن التاسع عشر في أعحال بموعة من الباحثين منهم: الألماني ماكس مولر (Max Mullar)، والفرنسي (Michel Breal)؛ و السويدي(Noreen)، و الأمريكي (Bloomfield)، و الإنجليزي (Firth)(5). ولا شك أن أهمية دراسة المعنى تكمن في دراسة اللغة؛ فاللغة ألفاظ ذات معان، ولو لا تلك المعاني ما كانت الدراسات اللغوية تصل إلى ما وصلت إليه، إذ المعاني لا تتناهى، والألفاظ متناهية، ثم حمّل على المشترك 
و الحركة المزدوجة والمثلثة حفظ التوازن بين المعاني والألفاظ، والعرب تقدّم المعاني على الألفاظ، وهذا ما ذكره ابن جني (ت 392 هـ): " أن العرب تهتم بالمعاني، وتقدّمها في أنفسها على الألفاظ..، فكأن العرب إنما تحلّي ألفاظها وتدبّجها وتشِيها وتزخرفها؛ عناية بالمعاني التي وراءها، وتوصّلاً بها إلى إدراك مطالبها،...، والمعاني أقوى عند العرب و أكرم عليها، وأفخم قدراً في نفوسها، والألفاظ خدم للمعاني؛ والمخدوم لا شكّ أشرف من

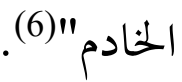

\section{الحركسـة فِّ اللغة :}

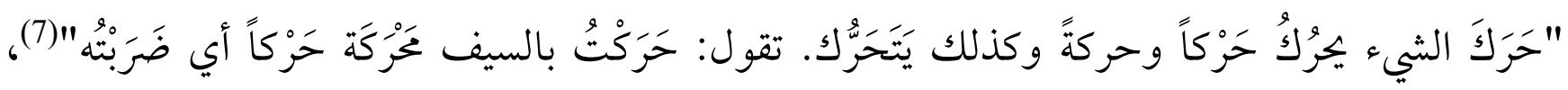
و"الحركة: ضد السكون: وحرّكته فتحرّك، ويقال: ما به حراك، أي حركة"(8)، و"من الباب الحاركان، وهما ملتقى الكتفين، لأنها لا يز الان يتحر كان"(9).

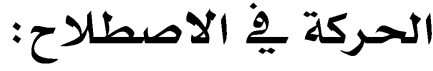

الحركات أو ما يسمّى (الصوائت)، هي الأصوات المجهورة التي يحدث في تكوينها أن يندفع الهواء عند النطق بها خلال الحلق والفم وخلال الأنف معها) أحياناً، دون أن يكون هناك عائق يعترض بجرى الهوى اعتراضاً. تاماً أو تضييق لمجرى الهو اء من شأنه أن يجدث احتكاكاً مسموعاً (10). "وإنها سميت هذه الأصوات الناقصة حركات، لأنها تقلق الحرف الذي تقترن به، وتجتذبه نحو الحروف التي هي أبعاضها، فالفتحة تجتذب الحرف نحو الألف والكسرة تجتذبه نحو الياء، والضمة تجتذبه نحو الواو، ولا يبلغ الناطق بها مدى الحروف التي هي أبعاضها، فإن بلغ بها مداها، تكملت له الحركات حروفا، أعني ألفا وياء وواوًا "(11). ولا شك أن هذه الحركات تقوم بمهمة كبيرة في العربية، فهي تعدّ أساساً لقوة السماع في لغة دعامتها المشافهة حتى الوصول إلى زمن التأليف والتدوين، فضلاً عن تسهيلها لعملية النطق وسرعة الانتقال فيها بين الحروف؛ 
لتوصل الكلام بعضه ببعض، وليس هذا فحسب بل تجاوزت ذلك لتنتقل إلى الجانب الدلالي وتنويع المعنى عند تقليب صيغ الاشتقاق المختلفة في حدود المادة ذات الجذر الواحد. "وزعم الخليل أن الفتحة والكسرة والضمة زوائد، وهن يلحقن الحرف ليوصل إلى التكلم به. والبناء هو الساكن الذي لا زيادة فيه. فالفتحة من الألف، و الكسرة من الياء، والضمة من الواو. فكل واحدة شيءُما ذكرت لك"(12). فلعل الخليل يريد بالبناء الأصل، وهو الأصوات الصامتة التي لا يمكن النطق بها إلا بعد أن تتخللها الأصوات الصائتة، وهذه الصوامت الأصول التي قامت على أساسها المعاجم العربية، فالمعنى العام تدل عليها الأصوات الصامتة، والمعاني الخاصة أو الفرعية تدلّ عليها الصوائت، كَتَبَ - كُتِبَ - كَاتَبَ -

\section{بين الدلالة والمعنى (Semantics \& Meaning)} ينقسم الآراء حول هذين المصطلحين: أ- هناك مَنْ يرى مِن الدارسين واللغويين بأن مصطلح الدلالة ومصطلح المعنى مترادفان. ب- آخرون يرون أن هناك فرقاً بين المصطلحيْنِ.

فمن القائلين بترادف المصطلحين (د. إبراهيم أنيس) في كتابه (دلالة الألفاظ) و (موريس أبو ناضر) في كتابه (إشارة اللغة ودلالة الكلام)، و(أحمد خختار عمر) في كتابه (علم الدّلالة)، فقد ذكر في تعريف علم الدلالة: "أما في اللغة العربية فبعضهم يسميه علم الدلالة وبعضهم يسميه علم المعنى والبعض الآخر يطلقون عليه اسم " السي|نتيك"(13). ويرى آخرون أنَّ هناك فروقاً بينها، فقد ذكر (د. هادي نهر) في كتابه (علم الدلالة التطبيقي في التراث العربي) أنَّ علم الدلالة أوسع وأشمل من المعنى، إذ يدخل ضمن الدلالة الرموز اللغوية (الألفاظ) وغيرها من أدوات الاتصال والإشارات والرموز والعلامات(14)، ودلالة اللفظ هي علاقته بمعناه، أي: ما ينصرف إليه هذا اللفظ في الذهن من معنى مدرك أو محسوس (15). 


\section{صفات الحركات}

في اللغة العربية ثلاث حركات قصيرة (Short Vowels) هي (الكسرة - الضمة - الفتحة)، وتقابلها في الألف باء العربية نظائرهما الثلاث (Long Vowels) وهي (ياء المدّ - واو المدّ - ألف المدّ)(16)، و الحركات القصيرة

$$
\text { التي تسمى أيضا بالحركات الأصلية، والتي هي: }
$$

الفتحة حَـ: عبارة عن فتح الشفتين عند النطق بالحرف، ويسمى بالفتحة أو النصبة، وإن امتدتْ تكون ألفاً، وإن قصر تكون فتحة أو بعض الألف، والفتحة تنبئ عن الكثرة، ويشار بها إلى السعة يدلك على ذلك أن الأخرس إذا أخبر عن شيء كثير فتح شفتيه، وباعد بين يديه إلى البعيد، وهي حركة خفيفة مستحبة يهرع إليها العربي ما وجد إلى الخفة سبيلاً، وهو عمل صادر عن الإرادة، وكلها أفعال مفتوحة العين؛ لأن الفتحة تدلّ على العمل الصادر عن الفاعل.

الضمة ـــ: عبارة عن تحريك الشفتين بالضم (تدويرهما)عند النطق بالحرف، فيحدث عن ذلك صوت خفي مقارن للحرف، فإن امتدت تكون واواً، وإن قصر تكون ضمة أو بعض الواو، والضمة ضد الفتح حيث تنبئ عن الضيق والدقة والقلة والتمكن والقوة والدوام والثبات، يدل على ذلك أنك تجد المقلل للشيء يشير إليه بضم يد أو فم كما فعل رسول الله (صلى الله عليه وسلّم) حين ذكر ساعة الجُمُعة وأشار بيده يقللها، فإنه جمع أصابعه وضمها ولم يفتحها، كما يظهر من صيغة (فعُل) في لزوم الفعل لموصوفه وثبوته وتمكنه؛ لأنها تدل على الغرائز والسجايا و الصفات الثابتة اللازمة لموصوفها(17). الكسرةِ_-_: عبارة عن انجرار اللحى الأسفل عند النطق بالحرف، وحدوث الصوت الخنفي يسمى كسرة، وإن امتدت يسمى ياءاً، وإن قصر يسمى كسرة أو بعض الياء(18)، وهي وسط بين الفتحة والضمة خخرجًا ومعنى، وبين الاتساع والضيق، وهي تدل على التواضع واللين والرقة وإظهار الضعف، وهي علم الإضافة، تدل على أن ما لحقته مضاف إليه (19). وكانت الكتابة العربية في عصر صدر الإسلام خالية من الحركات ونقاط الإعجام، وكانت المصاحف العثمانية برّّدة من كلّ علامة أو زيادة على نصّ القرآن الكريم(20)، وقد أخرج الداني (ت444هـ) عن الأوزاعي 
(ت 157 هـ) قال: سمعت يميى بن أبي كثير (ت129 هـ) يقول: "كان القرآن بجرّاً في المصاحف، فأول ما أحدثوا فيه النقَط على الياء والتاء، وقالوا: لا بأس به هو نور له، ثم أحدثوا فيها نقَطاً عند منتهى الآي، ثم أحدثو الفو اتح والخواتم"(21).

وأول من استعمل هذه التسميات للحركات الثلاثة أبو الأسود الدؤلي (ت 69هـ) عند نقطه للمصحف الشريف، وقد اجتمعت الروايات على أنه أول من استن العربية وفتح بابها وأنهج سبيلها ووضع قياسها(22)، فقد وجّه كاتبه في تنقيط الحروف بقوله: "خذ المصحف وصبغاً يخالف لون المداد، فإذا فتحت شفتيَّ فانقط واحدة فوق الحرف، وإذا ضممتهلا فاجعل النقطة إلى جانب الحرف، وإذا كسرتها فاجعل النقطة في أسفله، فإن أتبعت شيئًا من هذه الحركات غنّة فانقط نقطتين" (23).

المحور الثاني: الوظائف الصرفية للحركات: الحركة الصرفية هي الحركات التي تتو الى على فاء وعين الكلمة في العربية، وهي التي تؤدي وظيفة تغيير معنى الجذر اللغوي، أو على الأقل تحديد الاشتقاقات المولّدة من الجذر الواحد، كما في قولك: مُكْرِمِ ومُكْرَم لاسم الفاعل والمفعول من أكرم، والذي نبحث عنه في هذه الأمثلة تغيير معنى الجذر الواحد بسبب اختلاف حركات بنائه الصرفي.

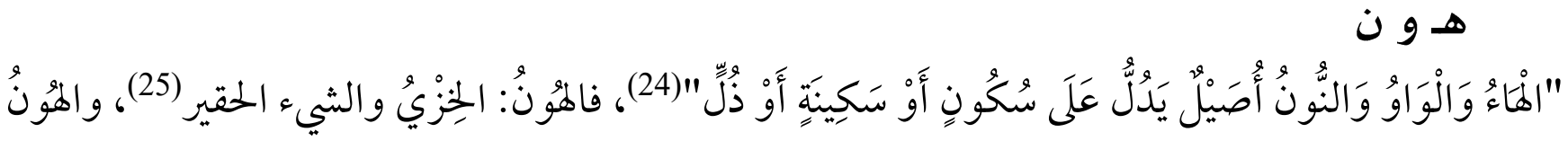

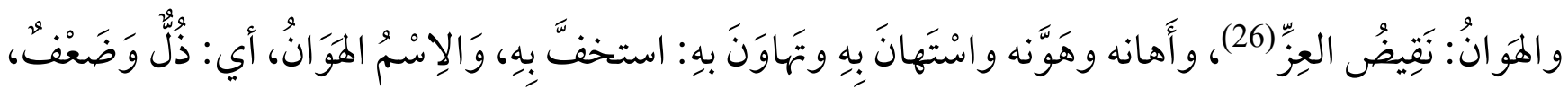

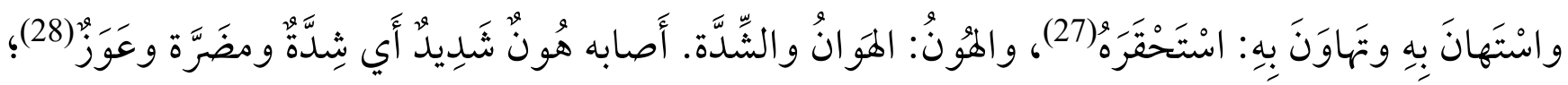

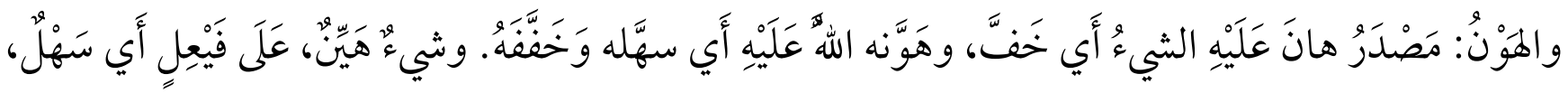

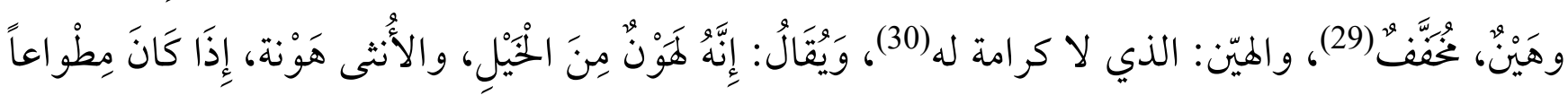

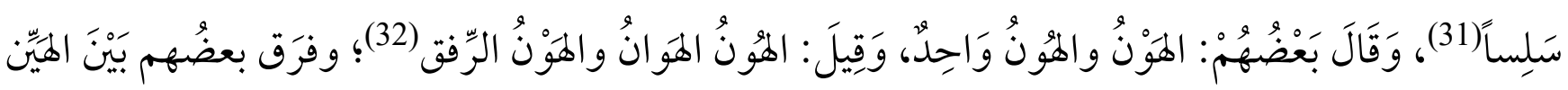




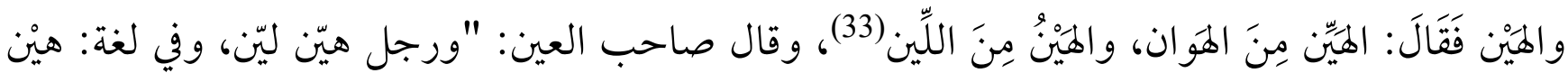

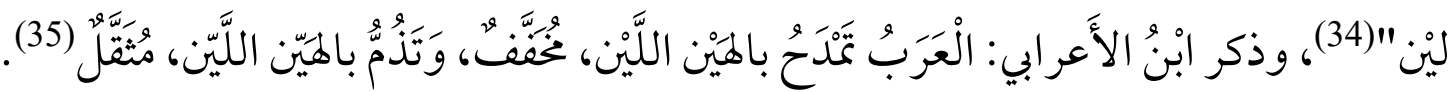

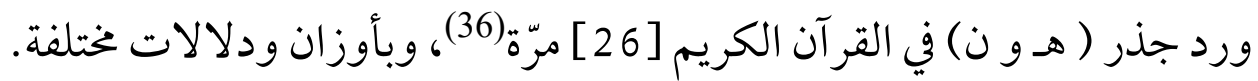

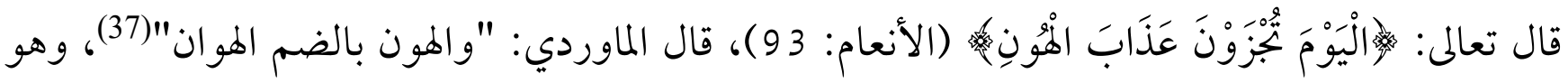

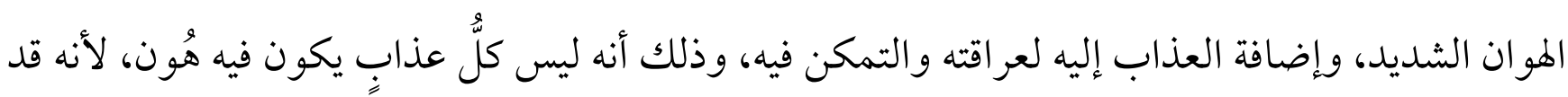
يكون على سبيل الزجر و التأديب(138).

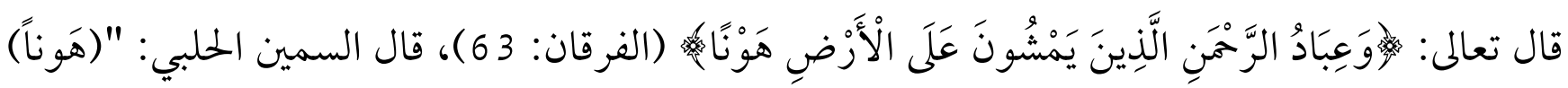

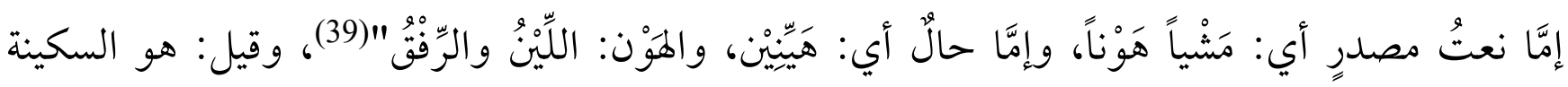
والتواضع، وهو الذي ليس فيه ضرب بالأقدام وخفق النعال فهو خخالف لمثي المتجبرين المعجبين بنفوسهم

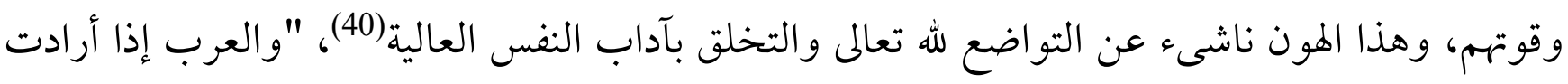

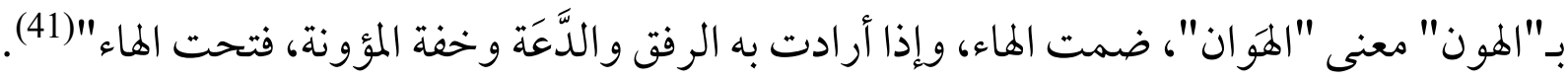

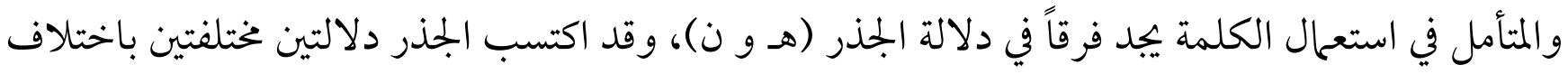
المصوت، فقد أكسب المصوت القصير (َح) في فاء الوزن المفردة معنى الخفة واللين ولا يخفى أن الفتحة أخف الحركات العربية في النطق، وقد ناسبت خفة الحركة معنى المفردة في الاستعال، بينما غيّر المصوت القصير

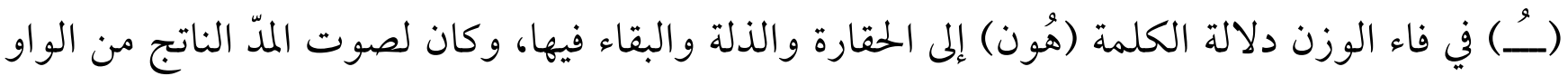
الساكنة والحركة المتجانسة قبلها إشارة إلى المكوث والخلود في هذا الذلّ، وهو العقاب المناسب لجريمة

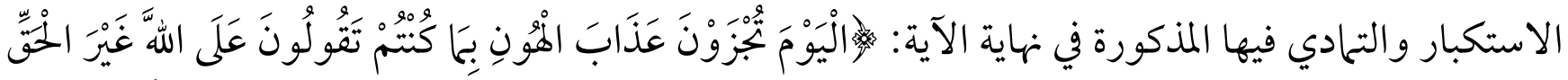

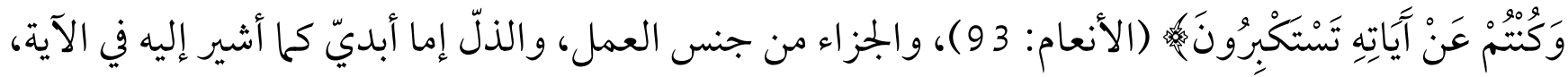

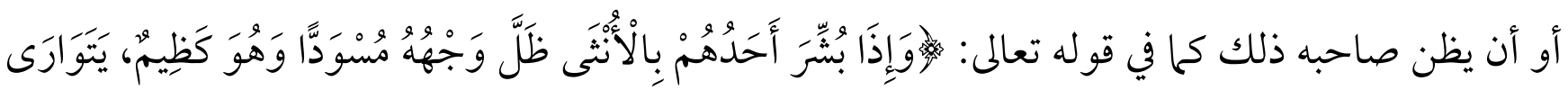

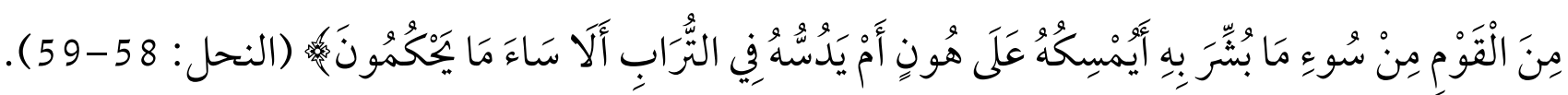




\section{Ј}

الحَاءو وَالََّاءُ في المُضَاعف له أَضْلَان: فالأول ما خالف العبودية وبرئ من العيب والنقص (42)، والثاني: خلاف البرد، يقال هذا يوم ذو حرّ، ويوم حارّ( 43 )، و الحورّ بالضم: نقيض العبد (44)، و"الحوّس: فرخ الحمام، والجانّ من الحيّات"(45)، وتحرير الولد: أن يفرده لطاعة الله عزّ وجلّ وخدمة المسجد، ولا يكون إلا للذكور (46)، و"قال الليث: تحرير الكتابة: إقامة حروفها، وإصلاح السقط "(47)، وَحُرُ الدَّار: وسطها، وطينٌ حُرُّ: لَا رَمْلَ فيه(48)،

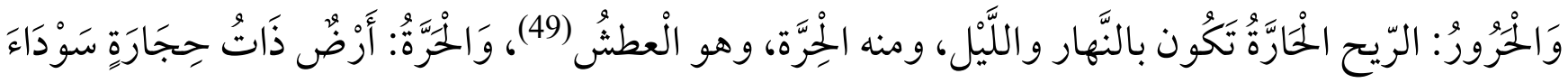
كأنها أحرقت بالنار (50)، والحرارة: حرقة في الفم من طعم الشيء، وفي القلب من التوجع (51)، واستحرّ القتل

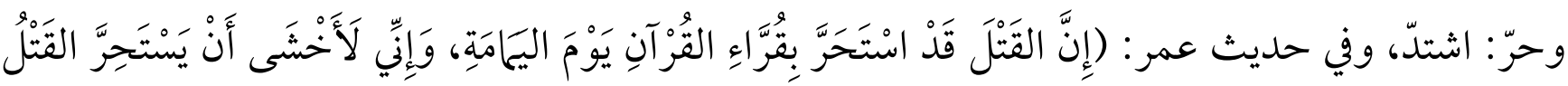
بِالقَُّّاء)(52)، و والحرير : ثياب من إبريسم (53). ورد جذر ( ح د ر ) في القرآن الكريم [26] مرّة(54)، وبأوزان ودلالات غختلفة.

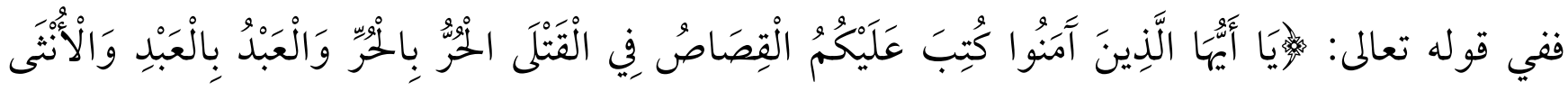

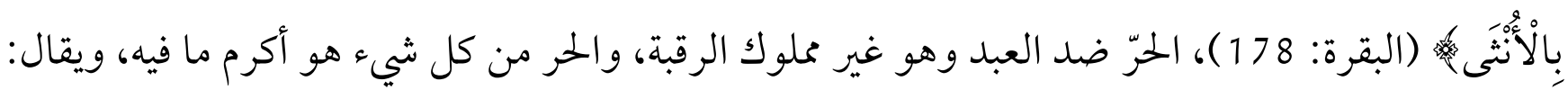
حر المال يعني أكرم ما في المال، و (الحر)" في الإنسان هو من لا يهكم رقبته أحد، و (الحر ) من البقول هو ما يؤكل غير ناضج، أي غير مطبوخ على النار، كالفستق واللوز، وجمعه أحرار وحرائر (55).

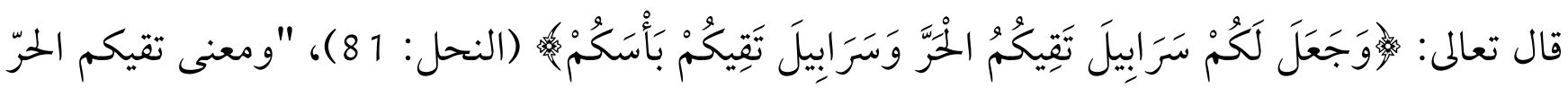
تدفع عنكم ضرر الحرّ، وخص الحرّ ولم يذكر البرد اكتفاء بذكر أحد الضدين عن ذكر الآخر؛ لأن ما وقى من الحرّ وقى من البرد. ووجه تخصيص الحرّ بالذكر أن الوقاية منه كانت أهم عندهم من الوقاية من البرد لغلبة

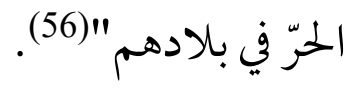

والمتأمل في استعال الكلمة يجد فرقاً في دلالة الجذر ( ح د ر)، وقد اكتسب الجذر دلالتين مختلفتين باختلاف المصوت، فقد أكسب المصوت القصير (ـــ) في فاء الوزن المفردة (الحوّم) معنى الثقل والتثبّت والاستقرار؛ والإنسان لا يقدَّر بثمن فلا يباع ولا يشترى، وليس لأحد حقّ في ذلك، وهو أبعد ما يكون عن النقص، وقد 
ناسبت هذه الصفات كرامة الإنسان التي وهبها الله إيّاه، ومعلوم أن الضمة حركة ثقيلة فهي تبرز قيمة الحرية لدى الإنسان، في حين ناسب المصوت القصير الفتحة (ـــ) (الحَرّ) صفة التطاير والارتفاع التي تصدر عن الحار، في إشارة إلى الخفة، ألا ترى كيف أن الماء المغليّ يتبخر ويتطاير ويرتفع عنه البخار ويتجه إلى الأعلى لخفتها، وقد ناسبت خفة الحركة معنى المفردة في الاستعمال.

\section{الدلالة النحصوية}

إذا أراد المتكلم أن يكون كلامه مفهوماً منسجحاً فلا بدّ أن يكون مو افقاً للقو اعد والأسس التي اتفق عليها أهل الصنعة، بعد أن بيّن اذلك على وفق ما جاء عن الفصحاء، ويرتب كلامه على أساس سبيلهم، قال الجرجاني (ت 17 هـ): "اعلم أن ليس "النظم" إلا أن تضع كلامك الوضع الذي يقتضيه "علم النحو"، وتعمل على قو انينه وأصوله، وتعرف مناهجه التي نهجت فلا تزيخ عنها، وتحفظ الرسوم التي رسمت لك، فلا تخل بشيء منها "(57) ولا يخفى أن بين علامة الإعراب وحركة الإعراب فروقاً، إذ علامة الإعراب عامة فمنها الحركة وغير الحركة من دلائل الإعراب، وأما حركات الإعراب عند النحويين فثلاث حركات: وهي الفتحة و الضمة والكسرة، وأما غيرها فعلامات تنوب عن الحركات عند تعذّر الإعراب بها كالواو أو الألف أو الياء، أو السكون أو النون أو حذف حرف العلة.

إنَّ حركات الإعراب ليست شيئاً زائداً أو ثانوياً بل لها وظيفة بيانية ونحوية يتضح بها المعنى، فعن طريق الحركات نعرف الصلة النحوية بين كلمة وأخرى، وهذا هو رأي جمهور علم)ء اللغة العربية، قال الزجاجي (ت 373 هـ): "فإن قال: فقد ذكرت أن الإعراب داخل في الكلام فها الذي دعا إليه واحتيج إليه من أجله؟ الجو اب: أن يقال: أن الأسماء لما كانت تعتورها المعاني، فتكون فاعلة ومفعولة ومضافة ومضافاً إليها، ولم تكن في صورها وأبنيتها أدلة على هذه المعاني بل كانت مشتركة، جعلت حركات الإعراب فيها تنبيىء عن هذه المعاني، فقالو ا: ضرب زيدٌ عمراً، فدلو ابرفع زيد على أن الفعل له، وبنصب عمرو على أن الفعل واقع به"(58)،

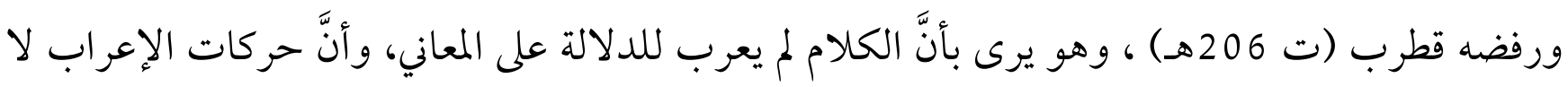


تدل على معانٍ حقيقية؛ وإنها الحركات للسرعة في الكلام والتخلص من التقاء الساكنين عند اتصال الكلام، وردّ عليه بأنه "لو كان كما زعم لجاز خفض الفاعل مرة ورفعه أخرى ونصبه، وجاز نصب المضاف إليه، لأن القصد في هذا إنها هو الحركة تعاقب سكوناً يعتدل به الكلام، وأي حركة أتى بها المتكلم أجز أته، فهو مخير في ذلك، وفي هذا فساد للكلام وخروج عن أوضاع العرب وحكمة نظام كلامهم" (59). فالحركة للحرف كالروح للجسد، والحركة الإعرابية شأنها شأن أي صوت في الكلمة لها قيمة وأثر في الإفصاح والإبانة عما في النفس من معنى، كما يُعرّف الإعراب بأنه اختلاف أواخر الكلمة، وذلك لاختلاف العوامل لفظاً أو تقديراً، فالمعنى يتضح عن طريق هذه الاختلاف في الحركات، فهو وسيلة من وسائل إظهار المعنى وإيضاحه، وهو مظهر من مظاهر الدقة في البيان، فالحركة ها مدلولها في الجملة العربية؛ لذلك الرفع هو علم الإسناد إذ أنَّ تعلَّق المسند بالمسند إليه، و النصب دليل وقوع الاسم فضلة في الكلام، وأوضحوا أنّ الفضلة تأتي بعد تمام معنى الجملة، والجر دليل الإضافة(60).

\section{الوظائف النحويـة للحركات}

الحركة تأتي تعبيراً عن المعاني المختلفة، وتفريقاً بين القصد والقصد الآخر، إذ لو لا الإعراب لتداخلت المعاني واختلطت وعجزت الألفاظ عن إيصال المعنى المقصود إلى السامع بدقة ووضوح (61)، وقد ذكر إبراهيم مصطفى أنّ در اسة علامات الإعراب من الضرورات؛ لأنها دوالّ على معانٍ، بقوله: "ونعلم أنَّ هذه الحركات تختلف باختلاف موضع الكلمة من الجملة وصلتها بما معها من الكلمات"(62). وبذلك يمكن القول: إنَّ الحركات لها وظيفة صوتية لوصل الكلام والتخلص من الوقف، ووظيفة نحوية هي تحديد موضع الكلمة وعملها ووظيفتها، فالعلاقة بين الحركات والنحو علاقة وطيدة، لأنّ النحو هو الإعراب، والإعراب تغيير أواخر الكلم، لذلك الحركات تكشف سرّ النحو وعلاقة الكلمات في الجملة، والتغيير في الحركة هو نتيجة للتغيير في المعنى. وقد سئل أحدهم: (مَنْ أسْعَدُ الناسِ؟؟) فأجابَ قائلاً: (مَنْ أَنْعَدَ الناسَ)، وهذه هي الدقّة المرجوّة وبها تحصل على الفرق الواضح في التعبير، فتغيير الحركة في (أسعد) في الجملتين حوّل الاسم (أسعدُ) إلى الفعل (أسعدَ)، 
و (الناسِ) من مضاف إليه إلى (الناسَ) مفعول به، وبه تحوّل معنى (مَنْ) الاستفهامية إلى (مَنْ) الموصولة، وبالتيجة تحولت الجمملة الطلبية (الاستفهامية) إلى جملة إنشائية (خبرية).

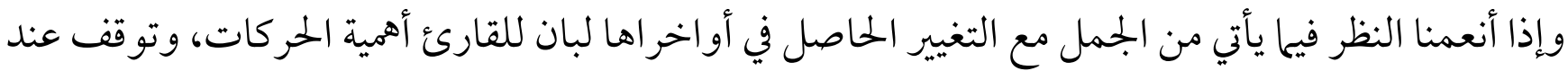

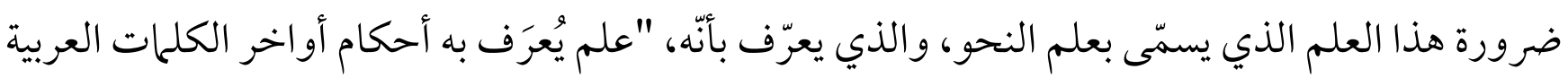

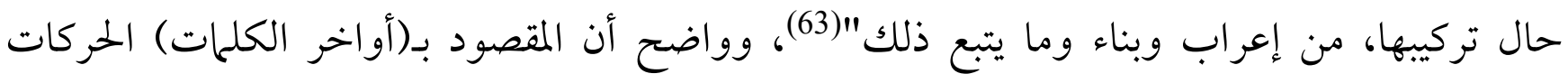

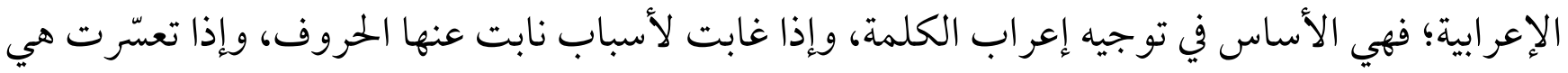
الأخرى، كان اللجوء إلى الرتبة، والآن لنتأمل هذه الجمل وننظر إلى معانيها من خلال حركاتها:

$$
\begin{aligned}
& \text { أَ- أَكْرَمُ الناسِ أحمدُ. } \\
& \text { ب- أََكْرَ الناسُ أحمَّ. } \\
& \text { ج- أَكْرِمِ الناسَ أحمدُ. } \\
& \text { د- أُكْرِمَ الناسُ أحمدُ. } \\
& \text { هـ- أَكَرَرَ الناسَ أحمدُ. }
\end{aligned}
$$

فالقارئ لهذه الجمل يحصل على معاني مختلفة فيا بينها، مع أن الكلمات نفسها وبالترتيب نفسه، إلا أن الحركات

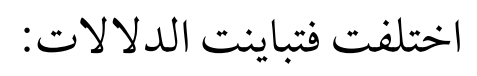

ففي جملة (أ)، أكرمٌ: هو المبتدأ وهو مضاف، و الناس: مضاف إليه، و (أمجد) خبرُ للمبتدأ.

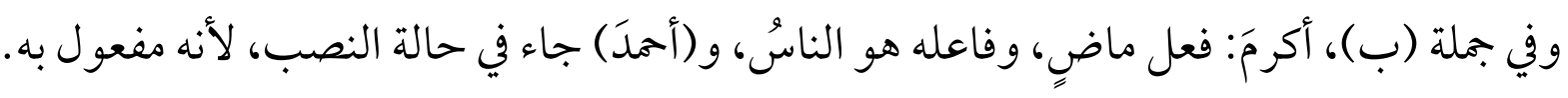
وفي جملة (ج)، أكرمٍ: هو فعل أمر مبني على السكون، وكسر لالتقاء الساكنين، وفاعله ضمير مستتر تقديره

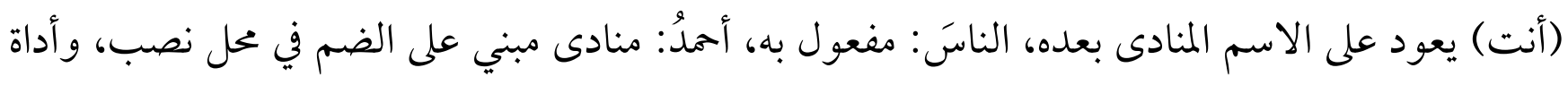

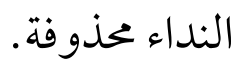
أما جملة (د)، أُكرَّ: هو فعل ماضٍ مبني للمجهول، الناسُ : نائب فاعل، أمحُ: منادى مبني على الضم في محل نصب، وأداة النداء محذوفة. 
وفي جملة (هـ)، أكرَّ: فعل ماضِ، الناسَ: مفعول به مقدّم، وأمدُ: فاعل مؤخَّر.

من خلال الاستقر اء وجمع المعلومات وصل البحث إلى بجموعة من الفوائد و النتائج منها: لا شك أن أهمية دراسة المعنى تكمن في دراسة اللغة؛ فاللغة ألفاظ ذات معان، ولو لا تلك المعاني ما كانت الدراسات اللغوية تصل إلى ما وصلت إليه، إذ المعاني لا تتناهى، والألفاظ متناهية، ثم حمّل على المشترك والحركة المزدوجة والمثلثة حفظ التوازن بين المعاني والألفاظ، والعرب تقدّم المعاني على الألفاظ، كما بيّن ذلك ابن جني. لا شك أن هذه الحركات تقوم بمهمة كبيرة في العربية، فهي تعدّ أساساً لقوة السماع في لغة دعامتها المشافهة حتى الوصول إلى زمن التأليف والتدوين، فضلاً عن تسهيلها لعملية النطق وسرعة الانتقال فيما بين الحروف؛ لتوصل الكلام بعضه ببعض، وليس هذا فحسب بل تجاوزت ذلك لتنتقل إلى الجانب الدلالي وتنويع المعنى عند تقليب صيخ الاشتقاق المختلفة في حدود المادة ذات الجذر الو احد، وكل حركة ها معناها ووظيفتها حسب موضعها في الكلمة، صرفية كانت أم نحوية. لم تكن الحاجة إلى بيان الحركات الصرفية والنحوية وكتابتها إلا بعد اختلاط القبائل بالعربية؛ فقد كان العربي يتلفظ الكلمة صحيحة بسليقته، ولا يتردد في ذكره الكلمة بشكل صحيح. إن العرب استخدمت الضمة للدلالة على التضام أو التَّلازم بين ركني الجملة الأساسيتين، والكسرة تدل على التو اضع واللين والرقة وإظهار الضعف، وهي علم الإضافة، والفتحة تنبئ عن الكثرة، ويشار بها إلى السعة، وهي حركة خفيفة مستحبة يهرع إليها العربي ما وجد إلى الخفة سبيلاً. هناك علاقة وطيدة بين الحركات والمعنى، والحركات لها وظائف نحوية وصرفية وكذلك صوتية، واللغة لا تتحدد مسار اتها في كثير من الأحيان إلا بالرجوع إلى هذه الحركات، فقد تقلبها إلى الضدّ؛ ولذلك نجد اعتماد المفسرين و الفقهاء في مو اضع كثيرة على الحركات في توجيهاتهم. 
لو لا الحركات لخّيّم الغموض على معاني بعض التعبيرات والكلم|ت، فتأتي هذه الحركات مبينة مفسّرة للمفردة، وبالتالي للتعبير، كالفرق بين اسم الفاعل واسم المفعول، والوصف والمصدر، وغيرها، فالحركة تأتي تعبيراً عن المعاني المختلفة، وتفريقاً بين القصد والقصد الآخر، إذ لولا الإعراب لتداخلت المعاني واختلطت، وعجزت الألفاظ عن إيصال المعنى المقصود إلى السامع بدقة ووضوح.

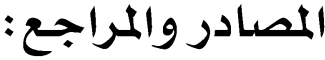

1. إبراهيم أنيس، دلالة الألفاظ، مكتبة الأبخلو المصرية، ط/5، 1984م. 2.

3. أبو بكر عبد القاهر بن عبد الرحمن بن محمد الجرجاني (ت 471هــ)، دلائل الإعجاز، تحقيق: مممود محمد شاكر، مطبعة المدني

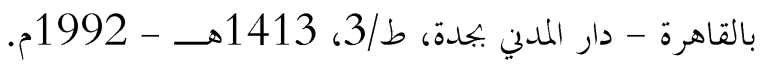

4. أبو بكر محمد بن القاسم (ابن الأنباري)، إيضاح الوقف والابتداء في كتاب الله عزّ وجلّ، تعقيق: محيي الدين عبد الرحمن رمضان،

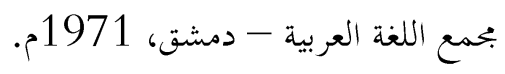

5. أبو جعفر أحمد بن محمد النحاس، إعراب القرآن، تحقيق: د. زهير غازي زاهد، ط/3/1)، 1985م.

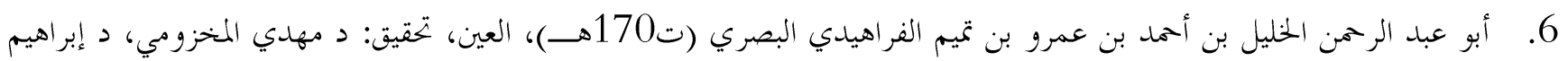

$$
\text { السامر ائي، دار ومكتبة الهلال، (د.ت). }
$$

7. أبو عمرو عثمان بن سعيد الداني (ت444هـ)، المحكم في نقط المصاحف، تحقيق: د. عزة حسن، دار الفكر - دمشق،

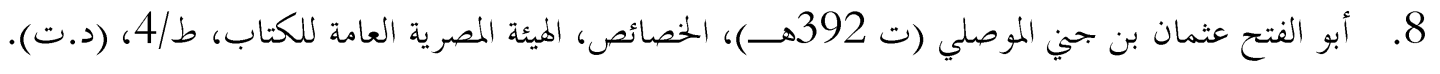

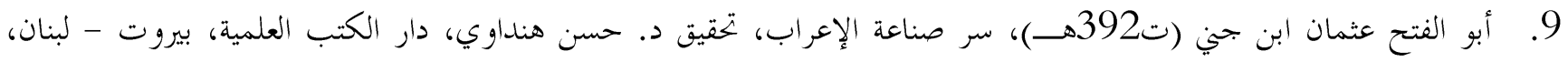

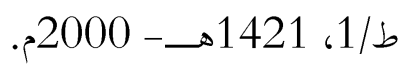

10. أبو الفرج محمد بن إسحاق بن محمد الوراق البغدادي المعروف بابن النديم (ت438هـ)، الفهرست، تحقيق: إبراهيم رمضان، دار

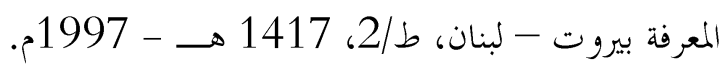

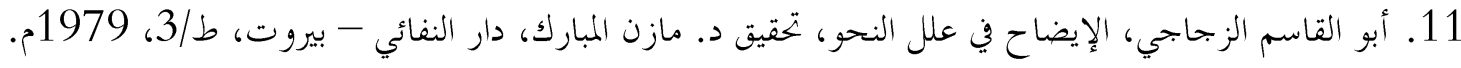

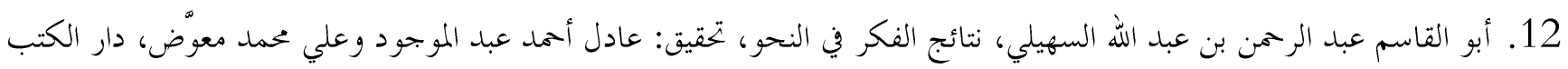

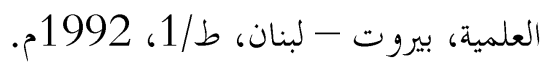

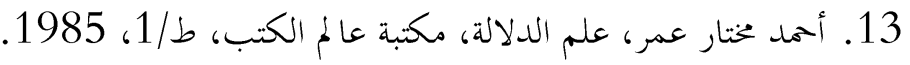

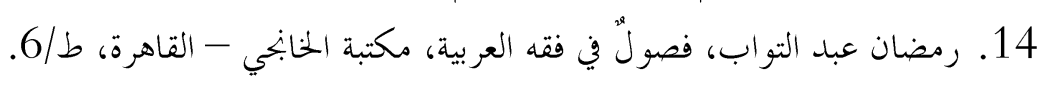

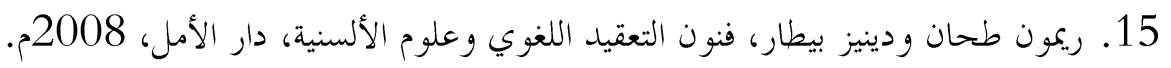




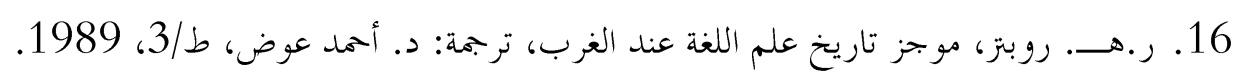

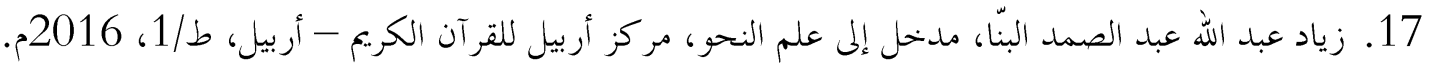

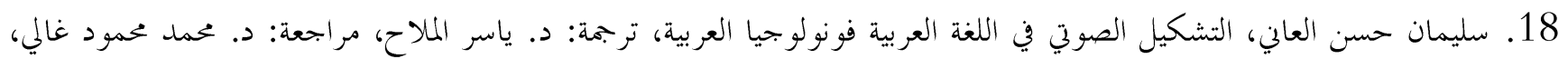

$$
\text { ط 1/1983، 1983. }
$$

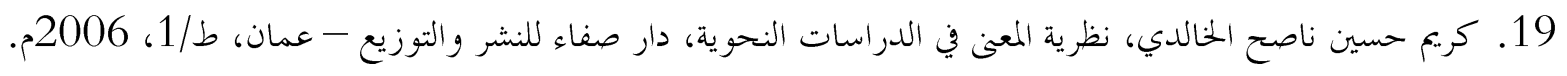

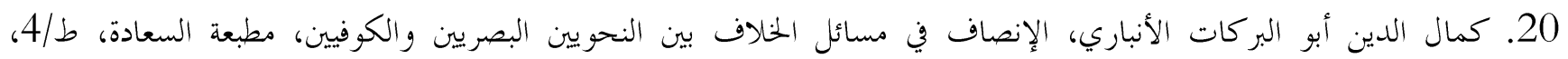

21. محمد بن أبي بكر بن أيو بن سعد شمس الدين ابن قيم الجوزية (ت751هـ)، بدائع الفوائد، دار الكتاب العربي، بيروت، لبنان،

$$
.(\cdot . \nu)
$$

22. محمد بن عيسى بن سَوْْة بن موسى بن الضحاك، الترمذي، أبو عيسى (ت 279هــ)، سنن الترمذي، تحقيق وتعليق: أحمد محمد

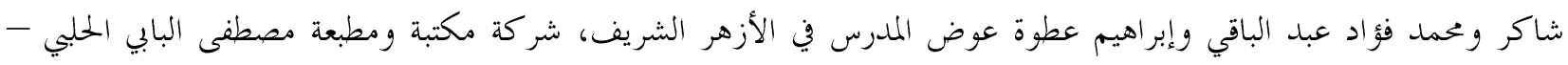
مصر، ط/2/2 مصند 1975م.

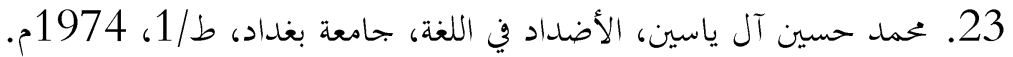

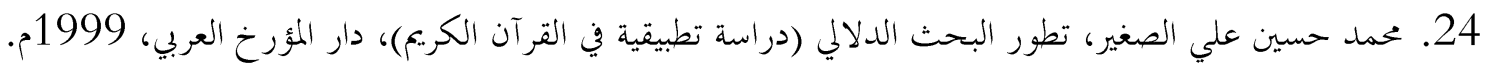

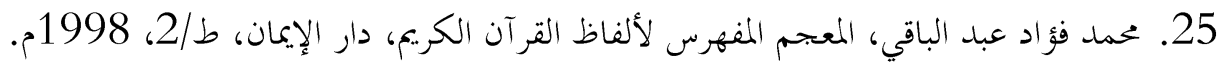

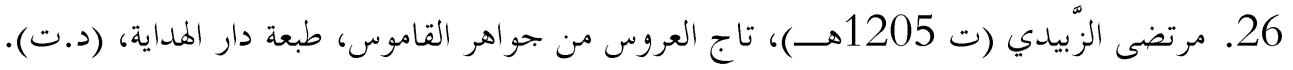

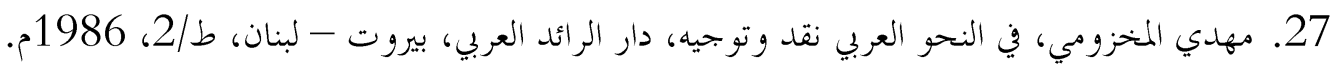

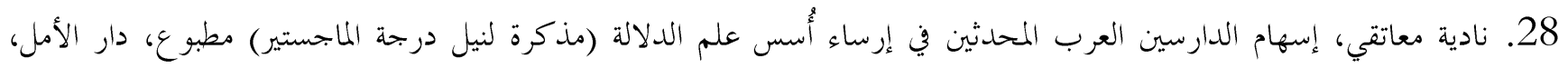
2006 29. هادي فر، الأساس في فقه اللغة العربية وأرومتها، دار الأمل، أربد - الأردن، ط/2005، 2005م.

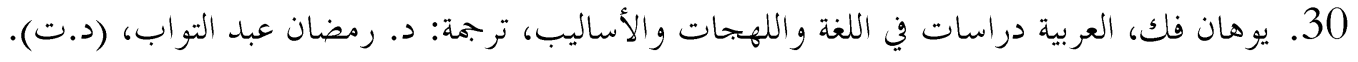

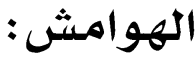

(1) إسهام الدارسين العرب المحديثين في إرساء أُسس علم الدلالة: 15.

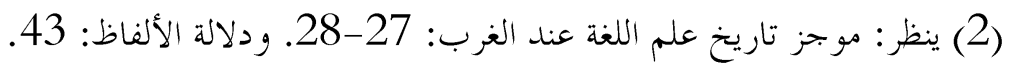

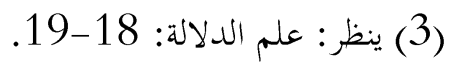

(4) فنون التعقيد اللغوي وعلوم الألسنية: 26.

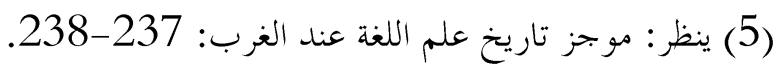

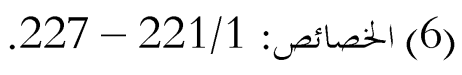




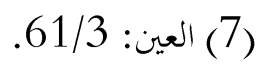

(8) الصحاح: 1579/4، وينظر: مقاييس اللغة: 45/2. (9) (45/2 مقاييس اللغة:

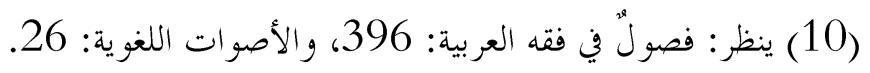

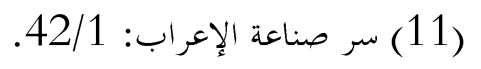

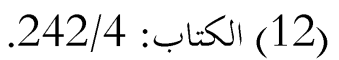

$$
\text { (13) (13) علم الدلالة: } 11 .
$$

(14)ينظر: الأساس في فقه اللغة العر بية وأرومتها: 227.

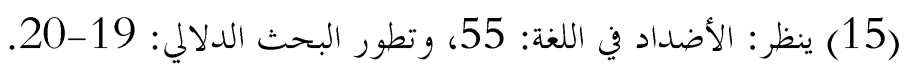

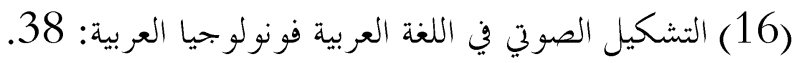

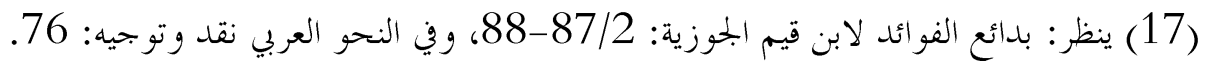

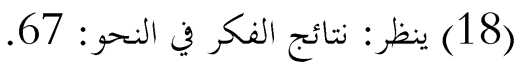

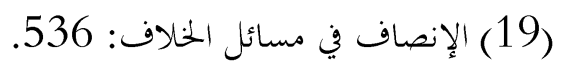

(20) ينظر: علم المصاحف: 137.

(21)المحكم في نقط المصاحف: 2.

(22) ينظر: العربية دراسات في اللغة واللهجات والأساليب: 21.

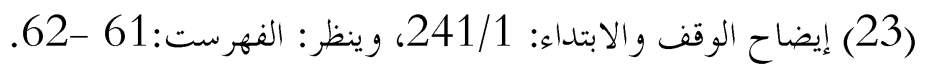

(24) مقاييس اللغة: 21/6.

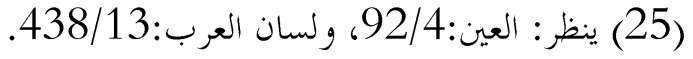

(26) لسان العرب:438/13.

(27) ينظر: العين:92/4، ولسان العرب:438/13 العران:438/13.

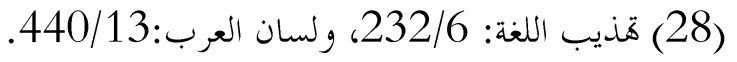

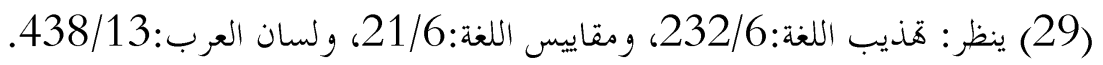

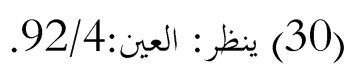

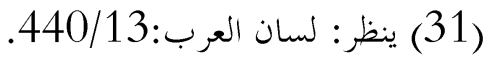

(32) مقاييس اللغة: 21/6.

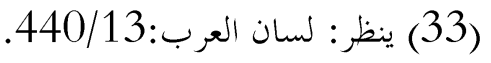

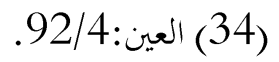

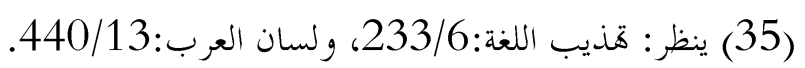

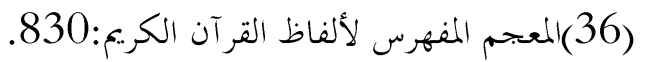


(37) (37) النكت والعيون:145/2.

(38) ينظر: الكشاف: 47/2، وأنوار التزيل وأسرار التأويل:173/2، والدرّ المصون في علوم الكتاب المكنون:40/5 والكيو

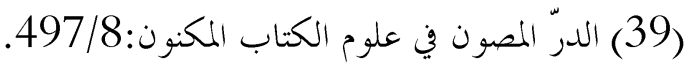

(40) ينظر: تفسير الجلالين:478/1، والتحرير والتنوير: 68/19.

(41) جامع البيان في تأويل القرآن: 541/11.

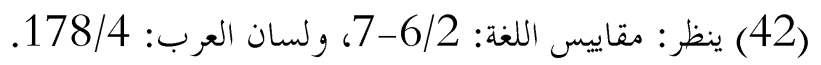

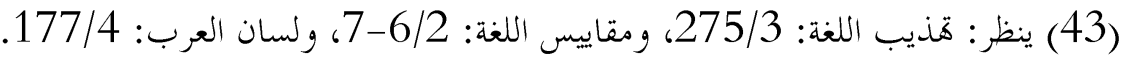

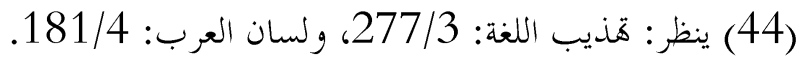

(45) ت تذيب اللغة: 276/3.

(46) ينظر: هذيب اللغة: 277/3، ولسان العرب: 181/4 كلايب (4)

(47) مَذيب اللغة: 278/3.

(48) بنظر : مقاييس اللغة: 6/2.

(49) ينظر: تذذيب اللغة: 275/3، ومقاييس اللغة: 6/2، ولسان العرب: 177/4 الفايسة.

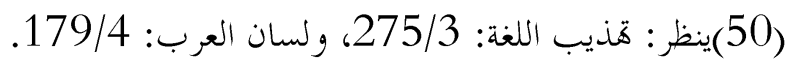

(51) ينظر: لسان العرب: 179/4.

(52) سنن الترمذي، باب، ومن سورة التوبة، رقم الحديث: 3103، 3103، 283/5.

(53) ينظر: تذذيب اللغة: 276/3.

(54) المعتم المفهرس لألفاظ القرآن الكريع:2410.

(55) ينظر: البحر المحيط، 129/2، وتفسير الشعراوي، 745/2.

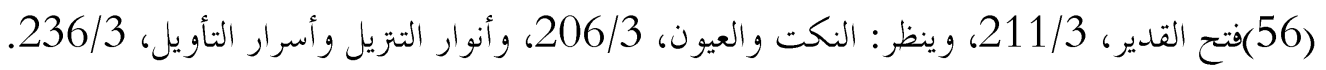

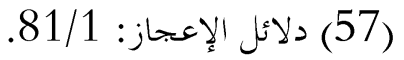

(58) الإيضاح في علل النحو:69.

(59) ينظر: المصدر نفسه:70.

(60)ينظر: نظرية المعنى في الدراسات النحوية: 217-228.

(61) ينظر: نظرية المعنى في الدراسات النحوية: 213.

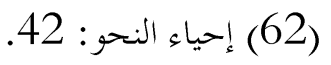

(63) مدنحل إلى علم النحو: 3. 